\title{
Effect of bezafibrate on the sequelae of acute experimental focal cerebral ischaemia
}

\author{
B S ASPEY, S EHTESHAMI, C M HURST, S PEREIRA, M J G HARRISON \\ From Reta Lila Weston Institute of Neurological Studies, The Middlesex Hospital, Mortimer Street, London
}

SUMMARY The possibility that the ability of bezafibrate to lower the oxygen affinity of haemoglobin might lead to an increased oxygen delivery to ischaemic cerebral tissue was explored in preliminary studies in two animal models. The combined morbidity and mortality of unilateral carotid ligation in the gerbil appeared to be reduced at two hours in bezafibrate treated animals. By four hours and thereafter the outcome was unaffected. Two hours after MCA occlusion bezafibrate-treated rats showed a significantly reduced rise in tissue lactate concentration $(p<0.01)$ suggesting less anaerobic metabolism had occurred in the ischaemic tissue.

Recent clinical trials have pursued the strategy of attempting to increase blood flow in the aftermath of acute stroke by haemodilution. ${ }^{12}$ Their lack of success has been blamed on the concomitant reduction in oxygen delivery consequent upon haemodilution. Attempts to increase the oxygen delivery to the brain during experimental ischaemia have been made using perfluorocarbons, though variable results have been produced. ${ }^{3-7}$

Thomas $^{8}$ suggested that the ability of the lipid lowering agent bezafibrate to lower the oxygen affinity of haemoglobin in vitro ${ }^{910}$ might be utilised. As a preliminary investigation of this possible strategy, we have studied the effect of a single injection of bezafibrate on acute focal cerebral ischaemia in two standard models.

\section{Methods}

Focal cerebral ischaemia was produced in anaesthetised gerbils (intra-peritoneal sodium pentobarbitol, $60 \mathrm{mg} / \mathrm{kg}$ ) by ligation of the left common carotid and right external carotid arteries. This technique produces variable degrees of ischaemia and neurological deficit ${ }^{11}$ and a cumulative mortality of $40 \%$ after one week (unpublished data). A total of 96 adult gerbils were subjected to this procedure, 48 of which had received a single intraperitoneal injection of bezafibrate

Correspondence to: B S Aspey, Reta Lila Weston Institute of Neurological Studies, The Middlesex Hospital, Mortimer Street, London WIN 8AA, United Kingdom.

Received 22 November 1988 and in revised form 3 July 1989. Accepted 10 July 1989
(MCP Pharmaceuticals Ltd), $10 \mathrm{mg} / \mathrm{kg}$ as a $1 \%$ suspension in methyl cellulose (itself a $10 \%$ solution in distilled water) one hour before carotid ligation. The other 48 animals received $\delta$ similar dose of methyl cellulose at this time. Operativ $\mathbb{N}$ procedures on each animal took 5-10 mins, after which the्ष 음 cutaneous incision was sutured and the animals allowed tळ recover under a heat lamp.

Clinical outcome and mortality rate were subsequently recorded at various intervals up to one week. Clinical statue was assessed by one observer and numerically graded a follows:

1 Normal behaviour or ptosis of one eye.

2 Right forepaw paresis or splayed limb.

3 Forced circling.

4 Tonic deviation of head and neck, fitting or moribund. 5 Death.

\section{Rats}

Twelve male Sprague-Dawley rats $(370-620 \mathrm{~g})$ were allowed free access to food and water before induction of anaesthesia with ether. Surgical anaesthesia was maintained with intraperitoneal urethane $1.25 \mathrm{~g} / \mathrm{kg}$ as a $25 \%$ solution in normal saline. The right femoral artery was cannulated for arterial sampling and blood pressure recording, and the left femoral vein cannulated for infusions. A tracheostomy was performed and the left common carotid artery ligated. Body temperature was monitored by a rectal probe and maintained by a heat lamp. After physiological baseline values were established for arterial blood pressure, $\mathrm{pO}_{2}, \mathrm{pCO}_{2}, \mathrm{pH}$, glucose and haematocrit, and core temperature, the left middle cerebral artery (MCA) was occluded by diathermy as previously described. ${ }^{1213}$

One hour before MCA occlusion, six animals received an intraperitoneal injection of bezafibrate similar to the gerbils $(10 \mathrm{mg} / \mathrm{kg})$ and the other six were untreated controls. Both groups received an intravenous infusion of $2 \mathrm{ml}$ of normal 1432 
Table 1 Numbers of bezafibrate-treated $(B)$ and control $(C)$ gerbils in the different clinical status groups at various times post carotid ligaton

\begin{tabular}{|c|c|c|c|c|c|c|c|c|c|c|}
\hline \multirow[b]{2}{*}{ Clinical status } & \multicolumn{2}{|c|}{$2 H R$} & \multicolumn{2}{|c|}{$4 H R$} & \multicolumn{2}{|c|}{$24 H R$} & \multicolumn{2}{|c|}{$48-72 H R$} & \multicolumn{2}{|c|}{ l week } \\
\hline & $\boldsymbol{B}$ & $C$ & $B$ & $C$ & $\boldsymbol{B}$ & $C$ & $B$ & $C$ & $B$ & $C$ \\
\hline $\begin{array}{l}1 \text { Normal behaviour or ptosis of one eye } \\
2 \text { Right forepaw paresis or splayed hind limb } \\
3 \text { Forced circling } \\
4 \text { Tonic deviation of head and neck, fitting or moribund } \\
5 \text { Death (cumulative) } \\
\text { Still unconscious after anaesthetic }\end{array}$ & $\begin{array}{r}21 \\
0 \\
2 \\
5 \\
1 \\
19\end{array}$ & $\begin{array}{r}13 \\
4 \\
5 \\
7 \\
4 \\
15\end{array}$ & $\begin{array}{r}29 \\
1 \\
2 \\
6 \\
9 \\
1\end{array}$ & $\begin{array}{r}29 \\
0 \\
6 \\
5 \\
7 \\
1\end{array}$ & $\begin{array}{r}28 \\
4 \\
2 \\
2 \\
12 \\
0\end{array}$ & $\begin{array}{r}29 \\
1 \\
4 \\
2 \\
11 \\
0\end{array}$ & $\begin{array}{r}29 \\
0 \\
0 \\
0 \\
18 \\
0\end{array}$ & $\begin{array}{r}29 \\
3 \\
0 \\
0 \\
17 \\
0\end{array}$ & $\begin{array}{r}28 \\
0 \\
0 \\
0 \\
19 \\
0\end{array}$ & $\begin{array}{r}25 \\
3 \\
0 \\
1 \\
19 \\
0\end{array}$ \\
\hline
\end{tabular}

saline over the first 30 minutes after occlusion, so that the controls could be used for another protocol. All the animals were maintained for two hours and then killed by immersion in liquid nitrogen for measurement of cerebral tissue lactate. Left and right whole hemispheric lactate levels were assayed as previously described, ${ }^{14}$ and expressed in $\mu \mathrm{mol}$ lactate $/ \mathrm{mg}$ hemispheric protein.

\section{Results}

Gerbil model (table 1)

Two hours after carotid ligation, about one third of the animals in both groups had not yet recovered sufficiently from the anaesthetic. At four hours all survivors, except for one animal in each group were conscious and could be examined for neurological deficit.

At two hours, one $(2 \%)$ treated and four $(8 \%)$ untreated animals were dead. By four hours the cumulative mortality involved nine $(19 \%)$ treated and seven $(16 \%)$ untreated gerbils and thereafter remained equal though there was a suggestion that at four hours there was less severe neurological deficit in the survivors in the treated group (table 1).

\section{Rat model (table 2)}

Pre-occlusion values for arterial blood pressure, $\mathrm{PaO}_{2}$, $\mathrm{PaCO}_{2}$, arterial $\mathrm{pH}$, glucose and haematocrit, and core temperature were all within normal ranges. In the six control animals, mean left (ischaemic) hemispheric lactate at two hours post MCA occlusion was $0 \cdot 84$, $0.019 \mu \mathrm{mol} / \mathrm{mg}$ protein (table 2 ), a mean rise of $116 \%$ above the nonischaemic right hemisphere $(p<0.001)$.

Table 2 Effect of bezafibrate on hemispheric lactate content 2 hours after occlusion of the left middle cerebral artery in the rat $(S D)$

\begin{tabular}{lccc}
\hline & \multicolumn{4}{c}{ Lactate $(\mu$ mol/mg protein) } \\
\cline { 2 - 4 } Group & $L$ & $R$ & $\%$ Rise \\
\hline Bezafibrate & 0.052 & 0.046 & $14.5 *$ \\
(n=6) & $(0.011)$ & $(0.007)$ & $(28.0)$ \\
Control & $0.084 \dagger$ & 0.040 & 116.5 \\
$(\mathrm{n}=6)$ & $(0.019)$ & $(0.013)$ & $(30.5)$ \\
\hline
\end{tabular}

*Difference from control $p<0.01$

+Difference between $L$ and $R$ hemisphere $p<0.001$.
In bezafibrate injected rats, the mean left hemispheric lactate content was significantly lower at $0.052,0.011$ $\mu \mathrm{mol} / \mathrm{mg}$ protein $(\mathrm{p}<0.01)$. This level represents a mean rise of only $14 \%$ above the corresponding nonischaemic right hemisphere $(0.046,0.007 \mu \mathrm{mol} / \mathrm{mg}$ protein), and is not significantly different from the nonischaemic hemispheres of either group.

\section{Discussion}

PET scanning of human patients in the aftermath of acute ischaemic stroke has suggested oxygen extraction may reach $100 \% .^{15}$ It is not clear, however, whether this average figure obscures areas below the spatial resolution of the equipment where increased oxygen availability might yet influence metabolism and outcome. Increasing cerebral blood flow by isovolaemic haemodilution as in the Italian Cooperative Trial ${ }^{2}$ produced no improvement in clinical recovery, and it has been suggested that this may relate to the reduced oxygen content of the blood after haemodilution. The possible benefit of inducing changes in the oxygen dissociation curve has been pursued in this preliminary study.

The uncertain significance of delayed recovery from anaesthesia in the gerbil model makes the early observations on only two thirds of the animals difficult to interpret. However, the possible clinical difference in outcome at two to four hours and the reduced rise in cerebral lactate two hours after MCA occlusion in the rat are compatible with a modified ischaemic result. As we had no direct measurement on the oxygen dissociation curve of haemoglobin in the bezafibrate treated animals, the precise nature of this beneficial response is not certain. However, these preliminary results suggest that further studies are warranted, for example: combining bezafibrate and haemodilution.

We thank MCP Pharmaceuticals Ltd for supplies of bezafibrate and Miss AL McCoy for the initial technical assistance.

\section{References}

1 Scandinavian Stroke Study Group. Multicentre Trial of 
Haemodilution in acute ischaemic stroke, I. Results in the total patient population. Stroke 1987;18:691-9.

2 Italian Acute Stroke Study Group. Haemodilution in acute strokes: results of the Italian Haemodilution Trial. Lancet 1988;i:318-21.

3 Peerless SJ, Ishikawa R, Hunter IG, Peerless MJ. Protective effect of fluosol-DA in acute cerebral ischemia. Stroke 1981;12:558-63.

4 Suzuki J, Fujimoto S, Mizoi K, Oba M. The protective effect of combined administration of anti-oxidants and perfluorochemicals on cerebral ischemia. Stroke 1984; 15:672-9.

5 Peerless SJ, Nakamura R, Rodriguez-Salazar A, Hunter IG. Modification of cerebral ischemia with fluosol. Stroke 1985;16:38-43.

6 Kolluri S, Heros RG, Hedley-Whyte ET, Vonsattel JP, Miller D, Zervas NT. Effect of fluosol on oxygen availability, regional cerebral blood flow, and infarct size in a model of temporary cerebral ischaemia. Stroke 1986;17:976-80.

7 Laycock JRD, Coakham HB, Silver IA, Walters FJM. Effect of carotid artery ligation and infusion of fluosol FC-43 emulsion on brain oxygen tensions. Stroke 1986;17:1242-6.

8 Thomas DJ. Haemodilution in acute stroke. Stroke 1985;16:763-4.

9 Perutz MF, Poyart C. Bezafibrate lowers oxygen affinity of haemoglobin. Lancet 1983;ii:881-2.
10 Wootton R. Analysis of the effect of bezafibrate on the oxygen dissociation curve of human hemoglobin. Febs Letts 1984;171:187-91.

17 Bosma HJ, Paschen W, Hossmann KA. Cerebral ischaemia in gerbils using a modified vascular occlusion model. In: Meyer JS, Lechner H, Reivich M, Ott EO, Aranibar A, eds. Cerebral Vascular Disease 3. Amsterdam: Excerpta Medica, 1981;280-5.

12 Tamura A, Graham DI, McCulloch J, Teasdale GM. Focal cerebral ischaemia in the rat. Description of technique and early neurophysiological consequence following middle cerebral artery occlusion. $J$ Cerebr Blood Flow Metabol 1981;1:53-60.

13 Dietis A, Ehteshami S, Harrison MJG, Perinpanayagam NI. The effects of isovolaemic haemodilution and intravenous glycerol on the sequelae of middle cerebral artery occlusion in the rat. J Neurol Neurosurg Psychiatry 1986;49:428-30.

14 Aspey BS, Ehteshami S, Hurst CM, McCoy AL, Harrison MJG. The effects of increased blood pressure on hemispheric lactate and water content during acute cerebral ischaemia in the rat and gerbil. $J$ Neurol Neurosurg Psychiatry 1987;50:1493-8.

15 Wise RJS. Bernardi S, Frackowiak RSJ, Legg NJ, Jones T. Serial observations on the pathophysiology of acute stroke. The transition from ischaemia to infarction as reflected in regional oxygen extraction. Brain 1983; 106:197-222. 